ENSAYO

\title{
EL VERDADERO ORIGEN DE AMNISTÍA INTERNACIONAL
}

\author{
Claudio Véliz
}

Amnistía Internacional no nació en 1961, como reza el mito de su creación. Nació siete años antes, una tarde de noviembre de 1954 en la mismísima sede londinense de la Brigada Internacional (B. I.), dedicada en esos días a proporcionar ayuda a los prisioneros políti$\cos$ (principalmente comunistas) en España. El autor de este ensayo participó en esa célebre reunión en el № 2 de Parton Street WC1, donde Alec Digges, dirigente de la B.I. expuso con cierto detalle su plan para una nueva iniciativa que luego se llamaría Amnistía, y más tarde Amnistía Internacional. Hoy, transcurridos más de cincuenta

\footnotetext{
Claudio Véliz Ph. D. en Historia Económica, The London School of Economics and Political Science. Profesor emérito de sociología de La Trobe University (Australia); Profesor emérito de historia en Boston University (EE.UU.), y Director emérito de The University Professors, Boston University (EE.UU.). Autor de Historia de la Marina Mercante de Chile (Ediciones de la Universidad de Chile); The Centralist Tradition of Latin America (Princeton University Press), y The New World of the Gothic Fox, Culture and Economy in English and Spanish America (University of California Press). Entre sus artículos publicados en Estudios Públicos están "Deportes Griegos e Ingleses”, "Simetrías y Divergencias en la Historia de Argentina y Chile”, "Un Mundo 'Made in England”” y “El Nuevo Mundo: Gesta Menor del Momento Castellano”.
}

Traducido al castellano por Alberto Ide para Estudios Públicos. La versión en inglés apareció en Quadrant (mayo 2007). 
años desde entonces, Claudio Véliz describe los individuos y las circunstancias responsables de la creación de esta organización tan visible e influyente hoy en día, así como los antecedentes de su modus operandum. El relato se inicia con el arribo del Winnipeg, herrumbroso barco de carga francés, a la bahía de Valparaíso en 1939.

\section{—a pleamar de la Guerra Fría encubrió tanto más que descabella-} das jugarretas de los agentes del KGB, y es probable que jamás lleguemos a enterarnos de cuántas iniciativas silenciosas, concebidas originalmente para dividir, influenciar, distraer o, en último término, reducir la resistencia a la embestida comunista, pasaron desapercibidas en ese entonces y permanecerán ocultas para siempre. Tal vez algunas de ellas fracasaron ignominiosamente, y muchas de las que tuvieron éxito en un comienzo desaparecieron más tarde bajo los escombros del Muro de Berlín. Pero unas cuantas sobrevivieron a la debacle de la órbita soviética y prosperaron en los años que siguieron. De estas últimas, Amnistía Internacional debe ser contada entre aquellas que lograron florecer de manera más convincente, tras sortear con destreza el difícil período de transición. Han transcurrido apenas tres años desde que, en 2004, se cumplió el cincuentenario de su idea rectora, y ahora resulta apropiado y de justicia, aunque sea de manera tardía, arrojar luz sobre sus verdaderos orígenes y rescatar de la oscuridad el nombre de su verdadero artífice.

Hace tres siglos, Giambattista Vico señaló que el postulado metodológico que gobernaba su Scienza nuova era que

La naturaleza de las instituciones no es otra cosa que su génesis [nascimento] en determinadas ocasiones y bajo ciertas vestiduras. Cada vez que la ocasión y la vestidura son tales y cuales, ésa y no otra será la índole de las instituciones que emergen [...] Las propiedades inseparables de las instituciones obedecen a las modificaciones o ropajes con que nacen [...] Basándonos en estas propiedades debemos asegurarnos, por tanto, que la naturaleza o nacimiento [natura o nascimento] fue así y no de otra manera.

Tres siglos más tarde, Isaiah Berlin se refirió a la importancia que tiene la percepción de Vico de que "La naturaleza del ser humano, así como la de todas las cosas, puede descubrirse al preguntarnos '¿qué nace, en qué 
momento, de qué manera?’”1. Esto puede o no ser elemento sine qua non de todas las cosas creadas, pero desde luego prevalece en entidades autónomas como Amnistía Internacional, alejadas del escudriñamiento externo y tal vez renuentes a apartarse demasiado de su propósito original en consonancia con las urgencias de la Guerra Fría.

En cierto modo, hace gracia observar que en 2001, cuando se conmemoró lo que parecía ser el cuadragésimo aniversario de la institución, no se vaciló en describir la versión oficial del origen de Amnistía Internacional - que figura incluso en el obituario de Peter Benenson- como un mito creacional $^{2}$. El texto reza así:

Según el 'mito creacional' de Amnistía Internacional, cierto día de fines de la década de 1960, un abogado británico llamado Peter Benenson se encontraba leyendo el Daily Telegraph mientras viajaba en el tren subterráneo de Londres, cuando reparó en un breve artículo acerca de dos estudiantes portugueses que habían sido detenidos por hacer un brindis por la libertad en un bar de Lisboa. Benenson decidió poner en marcha una organización dedicada a rescatar a prisioneros políticos y a otras víctimas de la represión gubernamental en todo el mundo ${ }^{3}$.

Esto era un mito tan pertinente y verídico el 2001, como ahora es oportuno y apropiado archivarlo reverentemente junto al mito del origen de Atenea y la fundación de Roma por Rómulo y Remo, y proceder a describir los individuos y circunstancias que fueron los verdaderos responsables de crear esta organización tan visible e influyente.

${ }^{1}$ Thomas Goddard Bergin y Max Harold Fisch, The New Science of Giambattista Vico, 1970, pp. 22-23. Véase también Isaiah Berlin, Vico and Herder: Two Studies in the History of Ideas, 1976, p. 59.

2 Peter Benenson (1921-2005), cuyo verdadero nombre era Peter Solomon, nació en Erfurt. Adoptó el apellido de su madre como homenaje a su abuelo materno ruso. Educado en Eton y en el Balliol College (Oxford), trabajó para los servicios de inteligencia en Bletchley Park durante la Segunda Guerra Mundial, ejerció la abogacía a partir de 1946, se incorporó al Partido Laborista y se transformó en un destacado miembro de la Asociación de Abogados Laboristas, postuló sin éxito a un escaño parlamentario en cuatro oportunidades, se convirtió al catolicismo en 1958 y llegó a ser el primer director de Amnistía Internacional en 1961.

${ }^{3}$ Jonathan Power, "In the Face of Repression”, The Guardian, mayo 12, 2001; Hugh O’Shaughnessy, The Independent, 28 de febrero de 2005; The Economist, obituario, 3 de mayo de 2005; Linda Rabben, “Amnesty's Roots”, extracto en internet de su libro Fierce Legion of Friends: A History of Human Rights Campaigners, 2002. 
Esta historia no se inicia en 1960 ni en 1954, sino durante las primeras horas del 3 de septiembre de 1939, cuando casi simultáneamente con la declaración de guerra en Europa, y sólo pocos días después de firmarse el pacto nazi-soviético, el Winnipeg, un viejo y herrumbroso barco de carga francés, apenas en condiciones de navegar y que transportaba a más de dos mil republicanos españoles refugiados de la Guerra Civil, fondeó en Valparaíso. La nave había sido fletada por Pablo Neruda, el poeta que más tarde sería el segundo chileno galardonado con el Premio Nobel, y que en ese entonces se encontraba en Francia cumpliendo funciones de cónsul especial para la inmigración española. Neruda había ejercido anteriormente el cargo de cónsul en Barcelona y Madrid hasta 1937, cuando su resuelto apoyo a la causa republicana le costó la destitución. Tras volver a Chile, a tiempo para colaborar en la campaña electoral de 1938 que llevó al poder al Frente Popular, regresó a Francia con los parabienes de Pedro Aguirre Cerda, el recién electo Presidente, e instrucciones de escoger entre los refugiados republicanos detenidos en campos de concentración en el sur de Francia una cantidad apropiada de trabajadores calificados, para que, junto a sus familias, se establecieran en Chile ${ }^{4}$.

El viaje del Winnipeg fue ampliamente publicitado en los medios locales, detallándose los conocimientos prácticos que los refugiados aportarían a su nuevo país. Entre ellos se mencionaba "mecánicos con experiencia”, lo cual llamó la atención de mi padre. En aquel tiempo él era dueño de Expreso Universal, una empresa de transportes que utilizaba camiones pesados Mack y Henschel, los que requerían atención mecánica especializada. En quince días había contratado los servicios de media docena de refugiados como conductores y mecánicos, dos de los cuales habían contribuido a la aplastante victoria de la división de tanques rusos T-26 del general Pavlov sobre los combatientes italianos en la batalla de Guadalajara.

A la sazón un impresionable niño de 9 años, muchísimo más interesado en el esquí que en la política, yo lo ignoraba todo acerca de la Guerra Civil española, lo que fue pronto remediado, sin embargo, mediante interminables y amenas conversaciones con los veteranos marcados por la guerra, quienes nos prestaron un servicio memorable desempeñando toda suerte de oficios, ya fuera como mecánicos en la empresa, ya fuera como maestros para toda suerte de arreglos en la casa. Su versión del conflicto concordaba con la del gobierno chileno del Frente Popular y su secuela hegemónica, el Partido Radical, que se mantuvo sin interrupción en el poder por otra década. Versión que fue reforzada, al menos hasta el comienzo de la Guerra Fría,

${ }^{4}$ Jaime Ferrer Mir, Los Españoles del Winnipeg: El Barco de la Esperanza, 1989. 
por los notables logros de una serie de talentosos refugiados del Winnipeg que ejercieron una influencia decisiva en la vida intelectual chilena, descollando con brillantez en una amplia variedad de ámbitos, desde la música coral y sinfónica hasta la arquitectura, el diseño de libros, la política, el teatro, la historia y las artes visuales.

Doce años más tarde, en 1952, ingresé a la London School of Economics and Political Science con miras a obtener un doctorado, con un bagaje de ideas tan claras y precisas acerca de la guerra civil que no dudé ni un momento cuando mis condiscípulos me pidieron que les ayudara con las traducciones para la Asociación de la Brigada Internacional (International Brigade Association, IBA). Desde el colapso de la República en 1939, esta organización se había dedicado a prestar auxilio a refugiados republicanos confinados en campos de detención en España, Francia y África del Norte. Después de 1945 dio un nuevo paso, abocándose a persuadir a las autoridades españolas para que llevaran a juicio a prisioneros políticos, en especial a aquellos que habían permanecido encarcelados desde fines de la Guerra Civil ${ }^{5}$. Entonces, al igual que ahora, me pareció una actividad extracurricular sumamente correcta, meritoria y espiritualmente gratificante, y me entregué a ella con el entusiasmo propio de los veintidós años.

Un atractivo adicional de esa tarea lo aportaba la personalidad de quien estaba a cargo de ella. Alec Digges era entonces el único irlandés de pocas palabras en el mundo, un hombre tenaz, inteligente y jovial, con quien era un agrado trabajar. Había nacido en Londres en 1914, pero se crió en Irlanda. Llegó a ser militante activo del Partido Laborista británico y del Partido Comunista irlandés. Habiéndose alistado como voluntario para luchar por la República, llegó a España en 1938 y fue destinado al 57 batallón de la XV Brigada Internacional. Aprobó un curso acelerado de ametralladoras y fue enviado al frente justo a tiempo para experimentar la ferocidad de la batalla del Ebro. Enfermo y herido, fue trasladado a un hospital de campaña y repatriado junto a otros miembros del batallón británico. Hombre de temple, al estallar la Segunda Guerra Mundial se enroló como voluntario en el ejército, se incorporó a los Granaderos, desembarcó en Normandía y avanzó con el ejército aliado hasta ingresar a Holanda, desde donde fue nuevamente repatriado, esta vez con una pierna menos. En Inglaterra, Alec

${ }^{5}$ En agosto de 1942, el Comité Ejecutivo de la IBA declaraba que "El auxilio y la liberación [son] las principales tareas de la [organización]”, The National Archives [UK], "Communists, suspected communists and communist organizations", "The International Brigade Association”, KV 5/46-58, serial 570a. En parte del documento se lee lo siguiente: "Los registros de vínculos con el Servicio de Inteligencia Secreta demuestran que durante la posguerra la mayoría de la correspondencia pasaba por las manos de Kim Philby". 
se transformó en un infatigable promotor de la Asociación de la Brigada Internacional, en especial de su campaña a favor de los prisioneros políticos recluidos en cárceles españolas.

En un principio, mis obligaciones se redujeron a labores de secretaría, y pasé mucho tiempo traduciendo peticiones dirigidas a diplomáticos y políticos en nombre de quienes figuraban en las listas cada vez más extensas de personas mantenidas en cautiverio sin ser enjuiciadas, hasta que Alec me hizo una oferta que no quise rechazar. Oferta no es la palabra precisa; preferible es invitación. Al tener pasaporte chileno, hablar español con acento chileno y ser demasiado joven para haber militado en la guerra civil, yo era la persona indicada para llevar a cabo una misión que ni Alec ni ninguno de sus camaradas o amigos parlamentarios estaban en condiciones de realizar, que era ingresar a España sin llamar la atención, como un mochilero cualquiera, vestido con un par de viejos lederhosen y demases, llevando las instrucciones y los fondos necesarios para contratar los servicios de abogados, pagar honorarios, sobornar a funcionarios y agilizar en general los complejos trámites burocráticos y judiciales que se requerían para llevar a los prisioneros a tribunales y, con un poco más de suerte, sacarlos de país.

Por aquel entonces yo también me ganaba unas cuantas libras extras redactando colaboraciones ocasionales para el New Statesman and Nation de Kingsley Martin, un semanario engalanado, a comienzos de la década de 1950, por la pluma de un número más que suficiente de pesos pesados de la intelectualidad y la política, cuya cercanía periodística me llenaba de orgullo y, lo que era más importante, me servía de excusa permanente para las que se transformaron en visitas de inusitada frecuencia a España. En honor a la profesión, efectivamente escribí dos o tal vez tres artículos, uno para el entonces Manchester Guardian (más tarde The Guardian), acerca de un viaje a dedo por España, y otros para el viejo Reynolds News y para el New Statesman, que trataban de política latinoamericana, y por lo menos uno, o quizás dos, sobre cómo fue recibida a nivel popular la firma del pacto de España con los Estados Unidos en 1953.

Fuera de eso, cumplí con lo que se me había encomendado procurando pasar inadvertido, a veces viajando en avión, otras veces ingresando por tren desde Francia, y en ocasiones haciendo dedo y caminando a través de Andorra, para luego descender por el Valle del Segre hasta la Seu d' Urgell e Igualada, continuando hasta Barcelona y Albacete, donde deposi- 
taba en manos amigas los paquetes puestos a mi cuidado, y luego pasaba por Madrid para reunirme con nuestros colaboradores, entre ellos periodistas extranjeros, quienes me suministraban información detallada y estratégica que de otro modo no habría podido conseguir. Mis primeras incursiones en la España del general Franco se remontan a 1953, un año en que la Asociación de la Brigada realizó una intensa labor benéfica que culminó, sin embargo, en una nota desalentadora.

El 19 de abril de 1953 la Asociación convocó a una reunión sobre “Ayuda a la Juventud Española”, celebrada en el Holborn Hall de Londres y presidida conjuntamente por Peter Benenson y Alec Digges ${ }^{6}$. El tema principal de la tabla era un informe de Benenson sobre los juicios de Sendrós y Aragó en Barcelona y Vitoria, a los que había asistido como observador con el patrocinio conjunto de la Asociación de la Brigada, el Consejo de Sindicatos (Trades Union Council) y la Sociedad de Abogados Laboristas (Society of Labour Lawyers). Los procesados eran treinta y ocho jóvenes detenidos en 1949, acusados de haber realizado actividades políticas ilegales - a favor del comunismo - usando como fachada clubes juveniles y sociedades deportivas. Las condenas exigidas por la fiscalía incluían quince años de prisión para tres de los acusados; doce años para otros tres; diez años para seis de ellos; ocho años para cuatro; seis años para siete; cuatro años para cuatro; dos años para nueve; y un año para $\operatorname{dos}^{7}$.

Los veredictos finales fueron relativamente indulgentes, variando de un máximo de cuatro años a menos, lo cual parecía confirmar la confianza que tenía Alec Digges en la eficacia de la presión internacional y la presencia de observadores de peso en los juicios, capaces de impresionar a la opinión pública internacional. Él se sintió doblemente complacido porque fue a instancias suyas que Peter Benenson, lo mismo que Maurice Orbach y el capitán Mark Hewitson, estos dos últimos parlamentarios laboristas, habían accedido a viajar a España cuando se les pidió que representaran a la Brigada en los procesos.

El problema, que en aquellos días Alec advirtió de inmediato, radicaba en que Orbach aparecía ostensible y entusiastamente asociado con el ala de extrema izquierda del Partido Laborista, a la vez que padecía de un alarmante entusiasmo partidista, mientras que Hewitson era un tipo afable, despreocupado y nada fuera de lo común, por lo que el publicitado compromiso de ambos con la causa de la Asociación de la Brigada difícilmente facilitaba el reclutamiento de otras figuras públicas de mayor fuste. Los intentos de

${ }^{6}$ International Brigade Memorial Archive, Marx Memorial Library, Catalogue 1986, Documents of Conferences, April 1953, Box 4, B/3. En adelante, IBMA, MML.

${ }^{7}$ IBMA, MML, Catalogue 1986, April 19, 1953, Box 4/B/3 y 4. 
Alec por establecer contactos con el destacado parlamentario laborista y abogado de la Corona (Queen's Counsel) F. Elwyn Jones, y con David Widdicombe, miembro de la Sociedad de Abogados Laboristas y potencial candidato del Partido Laborista al Parlamento, fueron desestimados de manera tan clara como cortés por Elwyn Jones, quien adujo que "no estaba disponible”, y por Widdicombe, quien señaló que

Hacer lo que usted me pide no sería compatible con mi calidad de miembro del Partido Laborista [...] Usted sabe que cuenta con mi absoluta simpatía y pleno apoyo en su afán de ayudar a los prisioneros políticos en España, pero en este caso particular se trata de una propuesta que no estoy en condiciones de suscribir.

Dicha propuesta consistía en redactar un proyecto de informe que sería presentado ante la Asociación Internacional de Abogados Democráticos (International Association of Democratic Lawyers), y que, según se esperaba, "serviría de acicate para emprender nuevas iniciativas a favor de las víctimas del régimen de Franco en muchos [otros] países”. La negativa de Widdicombe estaba en consonancia con la política del Partido Laborista de no cooperar con organizaciones de fachada del Partido Comunista.

Estas respuestas no amagaron el entusiasmo de Alec, sino muy por el contrario; plenamente consciente de que la publicidad es el manjar predilecto de los políticos, concentró los limitados recursos de la Brigada en un sistemático bombardeo a la prensa, los parlamentarios, los sindicatos y los funcionarios públicos con informes sobre el caso de Gregorio López Raimundo, un joven y popular dirigente que encabezó las huelgas de 1951 en Barcelona y aún permanecía recluido pese a que su condena original ya había expirado ${ }^{8}$. Alec escogió este caso porque tenía mayores probabilida-

8 “[...] lo primero era conseguir que la situación española fuera ampliamente publicitada, y captar el interés del Partido Laborista [...]” Véase National Archives, "Communists...", "The IBA" KV 5/46-58, Serial 552z, 15.11. En un informe de la policía relativo a un congreso de la IBA y Amigos de la España Republicana, celebrado el 28 de febrero de 1954, se señala que entre los detenidos en España se encontraba "un individuo cuyo nombre alcanzaría notoriedad: Gregorio López Raimundo. Durante la campaña que se organizó en su favor la Asociación logró conseguir el respaldo de todas las secciones del movimiento sindical y laboral" (National Archives, "Communists...", "The IBA”, KV 5/46-58, series 567C, M.I.5, Metropolitan Police, O.F.104/1, March 4, 1954, p. 3). 
des de atraer el tipo de interés periodístico y atención pública que inducirían, casi con seguridad, a parlamentarios indecisos y a otros personajes importantes a respaldar la campaña o, mejor aún, a acceder a demostrar abiertamente su apoyo a la causa viajando a España en representación de la Asociación de la Brigada.

La estrategia anterior se combinó con una campaña de "cadena” eficazmente organizada, mediante la cual se encomendó a un reducido grupo de simpatizantes confiables, en su mayoría identificados con el Partido Comunista y sus seguidores, que encontraran a dos amigos dispuestos a enviar cartas al embajador de España, al Ministro de Justicia de España, o al propio Gregorio López Raimundo, y que reclutaran a otros dos amigos para que cada uno de ellos repitiera el proceso. Aunque se interrumpió poco después, esta sencilla estrategia generó una avalancha de cartas, cuyo efecto psicológico antes y después de la firma del pacto entre España y los Estados Unidos no podía menospreciarse.

Una de las cartas que llegó a manos de López Raimundo mientras estaba en prisión, obviamente tras haber sido examinada con detención por las autoridades españolas, provenía del respetado historiador Christopher Hill. Escrita a mano y con su firma en papel con membrete del Balliol College, en una parte de ella se leía lo siguiente:

Me he enterado con horror de que su excarcelación, la cual según lo previsto debía hacerse efectiva en estos días, ha sido vetada por el Ministro de Justicia español, y de que a usted ya no se le permite ni siquiera recibir visitas [...] Tenga la certeza de que haré todo lo que esté a mi alcance para dar a conocer [estas transgresiones] [...] al círculo más amplio posible de mis conocidos en esta universidad y en otros ámbitos, de manera que puedan comprender cuán objetable es que nuestro país mantenga relaciones amistosas con un gobierno capaz de cometer tamaña y tan despótica injusticia $[\ldots]^{9}$.

Cabe aclarar que una de las principales dificultades para enviar observadores a España era que las fechas de los juicios se anunciaban normalmente sólo con uno o dos días de antelación, mediante una notificación apenas visible en el tablero de anuncios del tribunal local. Los parientes o amigos de los reos se turnaban para examinar estos avisos, y cuando se publicaba la fecha se apresuraban a dejar una nota en el buzón de la embajada británica, donde un funcionario amigo informaba al Foreign Office, el cual a su vez alertaba a un parlamentario - Maurice Orbach o el capitán

${ }^{9}$ IBMA, MML, April 24, 1953, Box 42 B/18. 
Hewitson—, que estaba preparado para volar a España con muy poco aviso previo.

Durante el otoño boreal de 1953, alentado por el resultado de la presencia de Peter Benenson en los juicios celebrados en Barcelona y Vitoria, Alec tomó la ofensiva y, sin esperar a los anuncios de procesos o a las comparecencias ante los tribunales, le pidió a Maurice Orbach que fuera a España con la misión específica de entrevistarse con Antonio Iturmendi, el Ministro de Justicia español, para hacerle llegar una protesta formal por la prolongación del arresto de López Raimundo, no sólo en nombre de la Asociación de la Brigada sino, además, de la Confederación Internacional de Sindicatos Libres. Como era de esperar, el Ministro se negó a recibir a Orbach. Al informar sobre esta visita, Sam Wild, presidente de la Asociación de la Brigada, se limitó a observar:

El señor Orbach subrayó, como también lo hicieron los señores Benenson y Widdicombe en nombre de la Sociedad de Abogados Laboralistas, enviados por nuestra Asociación para asistir a juicios anteriores, que el régimen de Franco es extremadamente sensible a la presencia de observadores en los procesos y a las opiniones expresadas por la clase trabajadora en el exterior $[\ldots]^{10}$.

Estas apreciaciones parecieron ser confirmadas más tarde por la publicitada excarcelación de López Raimundo, a quien se le permitió exiliarse en México en junio de 1954, donde, como era de predecir, reanudó su campaña contra el gobierno español. Animado por este desenlace, Alec estimó que había llegado el momento de conseguir el apoyo de Barbara Castle y Sidney Silverman, dos de los más influyentes parlamentarios del ala izquierda, quienes, supuso él, una vez adecuadamente informados, ayudarían a asegurar el necesario respaldo oficial del Partido Laborista.

Si bien mi experiencia era obviamente limitada, en esos días yo era la única persona al alcance de la mano que se había reunido recientemente con nuestros colaboradores en España y adquirido al menos cierto conocimiento, aun cuando incompleto, acerca de las medidas necesarias para organizar y financiar el intrincado proceso de llevar a juicio a los prisioneros, incluida

${ }^{10}$ Circular de la IBA firmada por Sam Wild (Presidente), Alan Gilchrist (Vicepresidente) y Alec Digges (Secretario), septiembre-octubre de 1953, IBMA, MML, Catalogue 1986, File B, 1953, B/62. 
la más importante de todas: la cooperación extraoficial y decisiva de algunos destacados periodistas y de por lo menos un funcionario que ocupaba un cargo estratégico en la embajada británica. Alec también consideró que el hecho de que apenas pocas semanas antes yo había sido elegido presidente de la Asociación de Estudiantes Graduados de la London School of Economics - a lo cual se agregaban mis poco comunes ancestros presbiterianos y mi amistad con Ted Castle, periodista y esposo de Barbara, quien concertó la reunión - le daba a mi participación por lo menos un viso de competencia y objetividad. También había que tener en cuenta, claro está, que, de los miembros del equipo que trabajaba en la campaña, yo era el único no alineado y no afiliado a ningún partido. Por estos motivos Alec estimó prudente recalcar que la entrevista debería tener un carácter estrictamente confidencial, para así evitar malentendidos si llegaba a trascender que sólo nosotros dos habíamos acudido a la Cámara de los Comunes para dar a conocer estos hechos a Barbara Castle y Sidney Silverman.

La reunión tuvo el resultado esperado. Fuera de manifestar su persistente apoyo moral y de recordarnos que sus firmas y las de otros noventa y seis parlamentarios laboristas ya habían sido estampadas en peticiones dirigidas al Ministro de Justicia español, los parlamentarios parecieron interesarse más que nada en la filiación política de los prisioneros que habían sido defendidos hasta la fecha por la Asociación. Alec se mostró desconcertado cuando lo instaron a referirse al tema, y le fue imposible no reconocer que, sin excepción, eran comunistas o sus actividades concordaban con los postulados y el programa del Partido Comunista español ${ }^{11}$. Tanto Barbara Castle como Sidney Silverman hicieron hincapié en que dado el clima político reinante, e independientemente de los méritos de la campaña emprendida por la Asociación de la Brigada, no era realista esperar que el laborismo otorgara el respaldo formal que Alec solicitaba.

Pese a que en rigor no profesaba un anticomunismo acérrimo, al Partido Laborista le preocupaban sus relaciones con los comunistas, actitud en la que influyó, acaso de manera decisiva, la publicitada crisis del Partido Laborista de Australia luego que Vladimir Petrov, espía soviético de alto

${ }^{11}$ En la Conferencia de la IBA y Amigos de la España Republicana, celebrada el 28 de febrero de 1954, sólo se consignaba a "comunistas, anarquistas, socialistas y sindicalistas [...]” entre los grupos en que se podía confiar para oponerse al régimen franquista, pero como lo ha explicado Hugh Thomas con cierto detalle, la gestación del Partido Comunista Español se encontraba indisolublemente ligada a socialistas y anarquistas que en ocasiones incluso consideraban la posibilidad de presentar una solicitud de ingreso al Comintern (The National Archives, "Communists...”, "The IBA”, KV 5/46-58, Serial 567C, Metropolitan Police, M.I.5, March 4, 1954, O.F.104/1, p. 5). Véase Hugh Thomas, The Spanish Civil War, 1977, capítulo 8, pp. 116-117. 
nivel, y su esposa desertaran a Occidente en abril de 1954. Era un secreto a voces que en el Partido Laborista de las antípodas no existía un consenso en cuanto a mantener relaciones con los comunistas, y en octubre de 1954 ya se estaban realizando gestiones que culminaron con la creación del Partido Laborista Democrático de Australia, de inspiración férreamente anticomunista, división que mantuvo a los laboristas alejados del poder por muchos años ${ }^{12}$.

Nuestros interlocutores recalcaron que no deseaban que en Gran Bretaña se repitieran los sucesos que hacia fines de 1954 amenazaron con destruir al Partido Laborista de Australia. Confirmaron su apoyo a la Asociación de la Brigada, pero también reiteraron la orientación categóricamente no comunista del laborismo. Más aun, al confirmar esta inclinación anticomunista, Silverman señaló que era igualmente importante que la opinión pública percibiese claramente que el partido no estaba "amparando a comunistas”. “Amparando a prisioneros”, interrumpió Alec, a lo cual la señora Castle replicó de inmediato: "Sólo prisioneros comunistas".

El dictamen de ambos parlamentarios fue claro: el respaldo del Partido Laborista era algo impensable mientras la campaña de la Asociación de la Brigada continuara orientándose principalmente a la defensa y protección de comunistas. Tal como ellos lo veían, al solicitar el apoyo formal del Partido Laborista, la Asociación ya estaba revelando su disposición a ampliar la gama de patrocinadores de la campaña, y lo que se necesitaba ahora era diluir aun más el tinte comunista extendiendo el manto protector a prisioneros de otras convicciones políticas.

Las cosas no se habían dado como Alec imaginó; no había sido una reunión alentadora y no pudo ocultar su desencanto. Avanzando lentamente hacia la parada de autobuses al otro lado de Parliament Square, hice lo que considero fue mi única contribución al génesis de la nueva entidad, al

${ }^{12}$ Una crisis que dio lugar a una memorable intervención del Primer Ministro Robert Menzies durante el debate parlamentario sobre espionaje soviético: "No puedo sino preguntarme cuántos miembros de la numerosa hueste de partidarios del laborismo en Australia, que sienten temor y aversión al comunismo y son sus enemigos declarados, han disfrutado el espectáculo en el que su líder, actuando en una doble calidad, les hace el juego a los comunistas en una tribuna pública, y por tanto con influencia pública, en un grado en que los comunistas, por sí solos, no habrían alcanzado en cien años” (Royal Commission on Espionage, Parliamentary Debates [Hansard], 3 Eliz II, House of Representatives, October 28, 1954, p. 2481). 
hacer presente a Alec dos hechos y formularle una sugerencia que, según creí, podría resultar útil.

El primero de ellos era que siendo los españoles muy legalistas, necesariamente invocaban la legislación vigente en todas las medidas oficiales. Durante la guerra civil, los abusos arbitrarios habían sido una práctica común en ambos bandos, pero una vez finalizado el conflicto, incluso los que podían parecer excesos despóticos cometidos por el gobierno, se basaban, sin excepción, en la ley.

El segundo hecho era que prácticamente todos los prisioneros por cuya suerte se interesaba la Asociación de la Brigada, habían sido detenidos o eran mantenidos en prisión preventiva conforme a lo dispuesto en la “Ley Especial de Represión de la Francmasonería y el Comunismo”, promulgada en 1939, y mi sugerencia, fundada en estos hechos, fue que tratáramos de averiguar si había algún masón bajo arresto cuya defensa y representación en los tribunales pudiera ser asumida por la Asociación, de la misma manera en que lo había hecho en los casos de otros prisioneros más políticamente comprometidos.

Al comienzo Alec manifestó sus reservas frente a una medida que, según sus aprensiones, apartaría la campaña de su principal objetivo moral, que era auxiliar a quienes durante la guerra civil habían luchado hombro a hombro junto a la Brigada Internacional. En un principio, la idea de extender esta ayuda a masones que pudieran haber mantenido una actitud imparcial, o incluso haber combatido dentro del bando nacionalista, le repugnó. Sin embargo, después de reflexionar y consultar a sus colegas, decidió hacer el intento, y fue así como una de las primeras oportunidades para proceder se nos presentó cuando nos enteramos de una noticia aleccionadora: los treinta y ocho prisioneros cuyas sentencias habían sido previamente reducidas, o que habían sido liberados tras los juicios de Barcelona y Vitoria celebrados en marzo de 1953, habían vuelto a ser detenidos reimponiéndoseles las condenas solicitadas originalmente por la fiscalía.

Ese solo hecho justificó mi regreso a España, pero me permitió asimismo inquirir más detalles acerca de la difícil situación que atravesaban los masones bajo la Ley Especial de 1939. El caso más reciente y mejor documentado era el de diecinueve masones arrestados en noviembre de 1952, principalmente en Barcelona, acusados de intentar restablecer una logia masónica en dicha ciudad. Algunos de ellos ya habían sido declarados culpables de un delito similar en 1942, habiendo pasado un tiempo en prisión. Para cuando llegué a España, en octubre de 1954, todos habían sido trasladados al penal de Carabanchel, al sur de Madrid. 
Utilizando nuestros contactos informales, logré dar con un joven abogado, el señor José Méndez Mayorga, contratado por organizaciones masónicas en México y los Estados Unidos, con quien organizamos la defensa de los prisioneros. Haciéndome pasar por el cuñado chileno de la hermana del profesor Nicolás Bayona Zaragoza, y acompañado por la propia señora Bayona Zaragoza, se me permitió ingresar al recinto penitenciario para visitar al catedrático, mi "pariente” lejano, y logré recabar valiosa información de primera mano sobre las circunstancias en que los acusados fueron detenidos y el trato que recibían en prisión. Quedó claro que su defensa estaba adecuadamente financiada y en buenas manos $^{13}$. El señor Méndez Mayorga prestó una valiosa colaboración y era poco lo que podíamos hacer para asistirlo financieramente o de otro modo, aunque si se tiene en cuenta la reunión que sostuvimos con Sidney Silverman y Barbara Castle, tenía asimismo garantías suficientes, algunas por escrito, de que contaría con nuestro apoyo moral y nuestro patrocinio, en caso de ser necesarios.

La misma llaneza que complace a los demócratas puede ser cicuta para los autócratas. Parecía una buena idea en ese entonces, pero la hábilmente orquestada publicidad de la Asociación de la Brigada, las manifestaciones públicas, las cuñas noticiosas redactadas por periodistas amigos, como también la avalancha de cartas dirigidas a funcionarios españoles exigiendo la liberación de López Raimundo, produjeron resultados desconcertantes, comenzando, sin duda, por la rápida liberación y partida al exilio del popular dirigente ${ }^{14}$. Como era de suponer, Alec atribuyó esta situación, al igual que las leves condenas recibidas un año atrás por José María Sendrós y sus treinta y siete camaradas, a la presencia de Peter Benenson en el juicio y a la consiguiente campaña de propaganda. No obstante, de acuerdo con tres de nuestros contactos más confiables y autorizados en España, la visión desde adentro era diferente. En visitas anteriores me había reunido con Camille Cianfarra, por muchos años jefe de redacción en España para el New York Times, y con Henry Buckley ${ }^{15}$, el corresponsal de Reuters en Madrid, quien me presentó a Bernard Malley, un hombre encantador, agu-

${ }^{13}$ IBMA, MML, Box 42, File C: 1954, C/45, C/46 y C/49.

${ }^{14}$ Gregorio López Raimundo fue liberado el 4 de junio de 1954 e inmediatamente se dirigió a México. La Asociación de la Brigada ya había enviado al Sr. David Widdicombe como observador a su juicio en julio de 1952. Carta de López Raimundo a Alec Digges, 10 de julio de 1954, IBMA, MML, Catalogue 1986, Box 42/C/35; también Box 42/C/32 y 43.

${ }^{15}$ Camille Cianfarra, por muchos años corresponsal en jefe para el New York Times en España, también escribió una serie de importantes libros, incluidos The Vatican and The War (1944) y The Vatican and The Kremlin (1950). Falleció, junto con otros cuarenta y cinco pasajeros, tras la colisión entre el Andrea Doria y el Stockholm frente a las costas de Nantucket el 25 de julio de 1956. Henry Buckley cubrió la Guerra Civil española para Reuters y The New York Times, y una vez concluido el conflicto escribió el libro The 
do, no pretencioso y en extremo bien informado, que conocía a todas las personas con que convenía trabar contacto en Madrid, mantenía excelentes relaciones con diplomáticos y funcionarios gubernamentales y, lo más importante, ocupaba un alto cargo en la embajada británica ${ }^{16}$.

Buckley me hizo saber que había conversado con Malley y Cianfarra sobre la temprana liberación de López Raimundo, y que el tema de la campaña de propaganda ni siquiera había salido a relucir; que la excarcelación no obedeció en absoluto a presiones desde Londres — lo cual le constaba a Bernard Malley-, sino única y exclusivamente a los renovados esfuerzos de España por recuperar su respetabilidad a nivel internacional, empeño que se veía favorecido en ese entonces por el empeoramiento de la confrontación entre las dos potencias mundiales a raíz de la Guerra de Corea.

La defensa de Europa Occidental frente a una eventual invasión soviética con fuerzas convencionales, que podrían barrer en pocos días con Alemania y Francia, forzaba a los Estados Unidos a establecer bases militares detrás de los Pirineos. A comienzos de 1952 se iniciaron las negociaciones formales, pero avanzaron con lentitud, en parte debido a las aprensiones que tenía la Casa Blanca de un acercamiento a tan conspicuo simpatizante de las potencias del Eje, y también porque suscribir con excesiva premura un acuerdo militar con España podría interpretarse como un reconocimiento de que Europa Occidental se encontraba prácticamente indefensa ante un ataque soviético. Por cierto que la renuencia nacionalista de Franco a ceder siquiera algo de soberanía para la instalación de bases militares extranjeras no facilitaba las cosas. Las conversaciones concluyeron con la firma del Pacto de Madrid el 26 de septiembre de 1953, el cual

Death of the Spanish Republic, que manifiesta su decidido respaldo al gobierno derrotado. Conoció a su esposa catalana durante la batalla del Ebro, y pasaron su luna de miel replegándose junto a las fuerzas republicanas a través de los Pirineos hasta territorio francés. Tras cubrir la Segunda Guerra Mundial, siempre para Reuters, volvió a radicarse en España junto a su mujer. Véase también el artículo dedicado a Buckley en Civil War de Hugh Thomas.

${ }^{16} \mathrm{El}$ interés de Malley por los asuntos españoles superó con creces los requerimientos de su cargo en el servicio exterior, actividad a la que dedicó el resto de su vida. Antes de incorporarse al servicio diplomático tradujo al inglés El Estado Nuevo de Víctor Pradera, publicado en Londres en 1939 con prólogo de S.A.R. el Príncipe de Asturias. Permaneció en España durante la Segunda Guerra Mundial y trabó una estrecha amistad con Sir Samuel Hoare (más tarde Primer Vizconde Templeton), embajador británico en Madrid entre 1940 y 1944, quien ayudó en forma importante a persuadir a Franco de mantenerse al margen de la guerra. Las últimas cartas de su correspondencia con Malley resultan francas y esclarecedoras. No creo ser el único que considera que Malley fue un observador excepcionalmente bien informado de la realidad española contemporánea; Hugh Thomas, el distinguido historiador, también lo conoció en la década de 1950, y no hace mucho intercambiamos impresiones sobre este tema tan grato y descubrimos que coincidían absolutamente. 
permitía que Estados Unidos utilizara y ampliara la base aérea y naval de Rota (cerca de Cádiz), así como las bases aéreas situadas en Torrejón (cerca de Madrid), Zaragoza (en el noreste de España) y Morón (cerca de Sevilla). A cambio, el gobierno norteamericano otorgó a España US\$ 226 millones en ayuda económica y militar.

Desde el punto de vista estratégico de las autoridades españolas, las prolongadas negociaciones que precedieron a la firma del pacto también encerraban la promesa de una normalización de las relaciones internacionales, y la lenidad exhibida en los juicios de Barcelona estaba en consonancia con sus esfuerzos por avanzar en este proceso. Era comprensible entonces la contrariedad que sufrió el gobierno franquista cuando no sólo se le negaron elogios por lo que estimaba había sido un generoso gesto suyo, sino además, y peor aun, tuvo que afrontar una campaña de propaganda y agitación hostil en su contra, orquestada por sus enemigos jurados. Una vez asegurada la firma del pacto con Estados Unidos, su reacción fue dar marcha atrás a la estrategia que, a todas luces, no había logrado granjearle el reconocimiento que a su juicio merecía, por lo que los treinta y ocho jóvenes comunistas y socialistas volvieron a ser detenidos, aduciéndose como pretexto legalista el que sus condenas no habían sido aprobadas por el Tribunal Militar Supremo, como lo disponía la Ley de 1939.

A comienzos de 1953, en las calles de Madrid se organizaron manifestaciones anti-británicas sorprendentemente agresivas y muy concurridas, para protestar contra la visita de la Reina Isabel a Gibraltar ${ }^{17}$. Meses más tarde ese mismo año, España cerró su consulado en el Peñón, un acto que con probabilidad traslucía su fundada confianza en la solidez de su nueva "relación especial" con Estados Unidos, la cual, como bien sabemos, prosperó con el tiempo, manteniéndose la potencia mundial como el aliado militar más importante y leal de España, y un actor clave en las gestiones para conseguir su readmisión a entidades internacionales como Naciones Unidas, la FAO, y por último, en 1982, pese a la oposición del Reino Unido y Francia, a la OTAN.

${ }^{17}$ En una carta dirigida a Lord Templeton, Malley le informó que había presenciado cómo unos veinte mil airados manifestantes nacionalistas marcharon hacia la embajada británica para protestar contra la visita de la Reina Isabel II a Gibraltar. Fueron reprimidos a duras penas por policías a caballo armados con sables, de los cuales él mismo tuvo que "escapar para salvar [su] vida”, pues se había mezclado entre la multitud para cubrir mejor las protestas. Carta de Bernard Malley a Lord Templeton, Madrid, 9 de mayo de 1954, MS Templewood XIII (26): 50-55, Department of Manuscripts \& University Archives, University of Cambridge Library. 
Decir que Alec se sintió decepcionado por estos acontecimientos sería subestimar groseramente la ira que sintió ante lo que consideró una abyecta traición por parte de la nación amiga y confiable, sobre la cual, con no poca de ayuda de Hollywood, él había conjurado una imagen que incluía a Henry Fonda en Las Uvas de la Ira, Paul Robeson cantando "Old Man River”, Humphrey Bogart en Casablanca, Caballero Sin Espada de Frank Capra y, lo más importante, la camaradería de los compañeros de lucha en la Brigada Abraham Lincoln, en especial durante la sangrienta batalla del Ebro.

La comparación era inevitable con su experiencia de agosto de 1939, cuando habiendo sufrido el bombardeo de la Legión Cóndor alemana tuvo que aceptar en silencio el lacerante oportunismo del pacto nazi-soviético. En esa ocasión, dada su inquebrantable lealtad al partido, no tuvo más remedio que obedecer. Ahora era distinto; nadie esperaba de él ese asentimiento disciplinado, y sólo se limitó a replantear el asunto a la luz de las nuevas circunstancias. Hasta la firma del pacto con Estados Unidos, sus amigos habían sido los mismos con los que había luchado contra Franco y Hitler, pero ahora el detestado régimen español se las había ingeniado para obtener el respaldo político y la ayuda económica de los Estados Unidos.

Alec vio el frente de batalla redibujado claramente, con las víctimas de la opresión capitalista e imperialista en todo el mundo en un bando, y los Estados Unidos y sus aliados, incluida España, en el otro. Dada semejante contienda, se dio cuenta de que asumir la defensa de los masones españoles había sido una iniciativa oportuna, al igual que simbólicamente correcta, porque abrió una puerta para que víctimas de injusticias en todo el mundo, pero en especial en países amigos de Estados Unidos, se unieran a sus ex compañeros de armas que se encontraban en prisiones españolas, formando así una gran coalición internacional de los oprimidos, cuyo calvario, cuando fuera dado a conocer de manera apropiada a la opinión pública, cubriría de oprobio y vergüenza a los adversarios de la Unión Soviética. La conclusión que apareció inexorable ante sus ojos era que la Asociación de la Brigada Internacional debería poner su experiencia al servicio de esa causa mayor.

Alec me daba instrucciones antes de emprender cada uno de mis viajes a España, y yo le presentaba un informe a mi regreso. Nuestras reuniones ofrecían oportunidades de sobra para tratar temas de esa índole, pero nunca antes y nunca más en el futuro se refirió a este asunto con mayor claridad y vehemencia que cierta tarde de fines de noviembre de 1954, cuando Peter Benenson y yo nos encontramos con Alec en el número 2 de Parton Street WC1, la sede londinense de la Asociación de la Brigada, 
dirección que merece llevar una placa conmemorativa por ser el sitio donde se fundó Amnistía Internacional.

Fue en ese lugar, durante aquella velada abundante en cigarrillos, café y whisky irlandés, y amenizada por una suculenta ración de animados debates, donde, que yo recuerde, por primera vez Alec expuso con cierto detalle su plan para una nueva iniciativa en la que, con el nombre de "Amnistía Internacional”, aglutinaría el llamado a una amnistía general para los prisioneros en España, adoptado originalmente durante la Reunión General Anual de la Brigada en 1952, la petición de amnistía formulada por López Raimundo en su primera declaración pública desde México, el internacionalismo decisivo, proclamado con vehemencia en la Internacional, himno de batalla del comunismo, y, lo más significativo para Alec, el sólido y permanente compromiso internacional tanto del antiguo Comintern como del nuevo Cominform ${ }^{18}$.

La honda vocación internacionalista de Alec quedó palmariamente demostrada cuando se alistó en forma voluntaria para tomar las armas en dos guerras, ninguna de las cuales afectaba en forma directa a Irlanda, su patria adoptiva. Stalin no tenía esa vocación; nunca pasó tiempo fuera de las regiones que luego conformarían la Unión Soviética, y sentía una instintiva y poderosa desconfianza hacia los extranjeros y los lugares foráneos, la cual se exacerbaba cuando se permitía que esos forasteros indignos de confianza — ¿“compañeros de ruta”? - asumieran tareas de importancia para la patria soviética. Stalin también habría coincidido con Tip O’Neill en pensar que toda la política es local, de ahí su tenaz reticencia a permitir que los asuntos internacionales lo distrajeran de los problemas internos.

Stalin estaba firmemente convencido de que su propio deber histórico consistía en garantizar la supervivencia del único y verdadero gobierno

${ }^{18}$ Pocos días después de llegar a México, el 1 de julio de 1954, López Raimundo hizo uso de la palabra durante una manifestación organizada por las Organizaciones Unidas en Ayuda de la España Republicana, ocasión en la que declaró que "la idea de una amnistía para los prisioneros políticos es acogida favorablemente por personas de todas las clases sociales [...], con el tiempo, los criminales que gobiernan [España] no podrán dejar de hacer caso a la presión mundial en favor de una demanda tan legítima del pueblo español”. Texto publicado en España Popular, México, 9 de julio de 1954. IBMA, MML, Catalogue 1986, Box 42/c/33. En 1919 Lenin fundó la Tercera Internacional, más conocida con el nombre de Comintern, consagrada a la tarea de promover la revolución mundial; fue disuelta por Stalin en 1946. Su sucesor no revolucionario durante la Guerra Fría fue el Cominform, fundado en 1947 y finalmente disuelto por Jruschov en 1956. 
revolucionario del mundo hasta ese momento, antes de siquiera pensar en la posibilidad de aventurarse en territorios extranjeros, convicción encapsulada en el célebre eslogan "socialismo en un solo país". Esta aproximación a los asuntos internacionales se consolidó entre 1919 y 1923 a raíz de los fiascos revolucionarios de Baviera, Hungría, Austria, Sajonia, Turingia y Hamburgo, los que no sólo confirmaron el odio mortal de Stalin hacia lo que consideraba el disparate romántico de la "revolución permanente" de Trotsky, sino que, peor aun, habían puesto en riesgo a la Unión Soviética al dejar los asuntos en manos de revolucionarios extranjeros impulsivos e ineptos.

Tales fueron los antecedentes de la renuencia de Stalin en 1936, cuando España se vio envuelta en la guerra civil, a comprometer a la Unión Soviética en la formación de Brigadas Internacionales para combatir en un país acerca del cual no sabía casi nada, y por una causa dudosamente relacionada con el interés nacional soviético. La idea original de reclutar voluntarios en todo el mundo para luchar por la república española la propuso el dirigente comunista francés Maurice Thorez, quien consiguió el respaldo de Willi Münzenberg, entonces influyente jefe de propaganda del Comintern. Incapaces de refutar las objeciones de Stalin desde la distancia, viajaron a Moscú para exponer sus argumentos, y tras prolongadas discusiones y muchas demoras pensaron que habían logrado su propósito al acordar que el flujo de voluntarios y la tan necesaria ayuda militar se canalizaran directamente a través del Comintern, sin involucrar ni al ejército ni al gobierno soviéticos.

El cazurro líder georgiano continuó oponiendo reparos y exigió pago al contado - en la forma de lingotes de la reserva de oro de la República Española que estaban siendo embarcados con destino a Odessa- por las armas enviadas a España. Incluso cabe la posibilidad de que al fin Stalin haya accedido no tanto debido a los pagos al contado, sino principalmente por temor a que le ganara terreno la cada vez más influyente izquierda trotskista española ${ }^{19}$.

Nunca antes el Comintern había estado en un primer plano tan visible como durante aquellos febriles meses en que se reclutó, armó y condujo a la batalla a varios miles de voluntarios provenientes de países de todo el

${ }^{19} \mathrm{Al}$ igual que Peter Benenson, Willi Münzenberg, cerebro de la propaganda comunista, nació en Erfurt en 1914. Murió asesinado cerca de Grenoble en 1940, casi con certeza por el NKVD. Stephen Koch, Double Lives: Stalin, Willi Münzenberg and the Seduction of the Intellectuals, 1944, pp. 332-344; Hugh Thomas, "The Spanish Civil War. Spain, 1936-1939”, 1979, p. 1601; también, Hugh Thomas, The Spanish Civil War, 1977, capítulo 27, pp. 452-464. Véase también Alan Bullock, Hitler and Stalin, 1992, pp. 532-533. 
orbe, que acudieron en masa a las oficinas de esa organización para incorporarse a las Brigadas ${ }^{20}$.

Respecto de España, la operación propagandística de Münzenberg eludió con astucia las reservas de Stalin, y reactualizó la decrépita retórica revolucionaria del Comintern inyectándole una buena dosis de ambigüedad, más que una pizca de remozada imagen y consignas del Frente Popular, y lo hizo irrumpir en el campo de batalla bajo un mar de estandartes rojos y enardecidas versiones corales de la Internacional. Este mundo revolucionario, fabricado por el Comintern y puesto en marcha por la maquinaria propagandística de Münzenberg, fue el que acogió al voluntario irlandés Alec Digges, que entonces contaba 24 años. No sorprende que esta imagen haya tenido tan grande influencia en el joven, que no sólo sobreviviría a la derrota que, tal como Stalin acertadamente había anticipado, pasaría a engrosar la colección de fracasos del Comintern, sino que, lo más importante, emergería airosa e inmune a las ignominiosas exigencias del Pacto nazi-soviético y franquearía la Segunda Guerra Mundial y sus secuelas sin verse afectada por la oleada de nacionalismo estalinista que en 1943 y 1944 abolió un Comintern al borde del colapso y, a su vez, el hasta entonces sagrado himno de la URSS, la Internacional, considerado ahora teórico y simbólicamente defectuoso.

Un nuevo himno fue compuesto en el espacio de unos pocos días de “ardiente frenesí de estajanovismo musical”, y entre los autores de la letra se contaban Molotov y Voroshilov, y de la música, Shostakovich y Prokofiev $^{21}$. Ni la palabra internacional ni el concepto de revolución mundial figuraron en la nueva letra, dedicada principalmente al ensalzamiento patriótico de la Rusia soviética y su territorio ancestral. La desaparición del Comintern y el abandono de las arengas leninistas a favor de la revolución mundial fueron exhibidos como gesto de buena voluntad hacia los aliados en tiempos de guerra, pero acaso el motivo principal fue el deseo de Stalin de eliminar una tribuna para las opiniones de extranjeros que no eran incon-

20 "Cada partido comunista recibió instrucciones de reclutar cierta cantidad de voluntarios. La mayoría de los dirigentes más capacitados del Comintern fueron destinados a esta tarea. El futuro Mariscal Tito, Josip Broz, por ejemplo, se encontraba en París organizando, desde un pequeño hotel situado en la orilla izquierda del Sena, el flujo de reclutas a través de su así llamado 'ferrocarril secreto', que proporcionaba pasaportes y fondos a voluntarios de Europa del Este” (Hugh Thomas, The Spanish Civil War, 1977, p. 454).

${ }^{21}$ Simon Sebag Montefiore, Stalin: The Court of the Red Czar, 2003, pp. 406407. 
dicionales de Moscú, y potencial fuente de un aventurismo internacional, costoso e impredecible ${ }^{22}$.

El problema era que si bien no se podía disimular la participación de los comunistas en el conflicto interno español, había que ganarse el favor de la opinión pública fuera de España para que respaldara la causa republicana y reaccionara con generosidad a las solicitudes de fondos, armas y combatientes, objetivo improbable de alcanzar si aparecía patrocinado en su mayor parte por fervientes revolucionarios. En un principio Münzenberg utilizó el Workers International Relief y a sus filiales, dependientes del Partido Comunista, pero su impacto en la opinión pública internacional fue muy decepcionante. Este revés empujó a Münzenberg a aportar dos nuevas ideas que revolucionaron la política mundial por el resto del siglo XX hasta nuestros días. Como lo ha señalado Hugh Thomas, "él realmente inventó al compañero de ruta"23, y es más, también inventó las front organizations (organizaciones de fachada).

Münzenberg percibió, de manera casi instintiva, que las sociedades que habían abrazado la modernidad industrial y secular, padecían de un agotamiento crítico de la justificación moral que constituye "una de nuestras más profundas necesidades, uno de nuestros impulsos humanos más poderosos y esenciales, y que es ignorado a nuestro riesgo y costo" 24 . Pese a no poseer ningún conocimiento formal de teología, historia o sociología, comprendió en la práctica la importancia de la "virtud moral" (righteousness) en la vida humana. Percatándose acertadamente de que este ingrediente fundamental escaseaba en los estratos medios y superiores de la sociedad europea occidental, desplegó su formidable organización propagandística, concentrándola en la tarea de producir, para llenar el vacío, un número suficiente de causas virtuosas que fueran convincentes, inmaculadas y enaltecedoras.

${ }^{22}$ Según Milovan Djilas, Stalin disolvió el Comintern porque "se había transformado en un estorbo, como también en un anacronismo, cuyos miembros que habían emigrado intentaban promover políticas que no estaban en consonancia con [las de Stalin]" (Bullock, Hitler and Stalin, 1992, pp. 792-793). Gran parte de lo anterior se aplica también a la decisión, adoptada en 1947, de crear el Cominform, no como un Comintern revolucionario resucitado sino como un instrumento cuidadosamente diseñado para "montar una ofensiva conjunta de propaganda contra la aceptación del [Plan] Marshall” y asegurar un control más férreo sobre sus satélites de Europa del Este (Bullock, Hitler and Stalin, 1992, pp. 925-926).

${ }^{23}$ Hugh Thomas, The Spanish Civil War, 1977, p. 341, n. 3; una opinión compartida por la esposa de Münzenberg, la legendaria Babette Gross, quien lo describió como "el santo patrono de los compañeros de ruta", Andrew Campbell, "Double Lives: Three Australia Fellow Travellers in the Cold War”, 2007, pp. 44-45.

${ }^{24}$ Stephen Koch, “Lying for the Truth: Münzenberg \& The Comintern”, 1993. 
Münzenberg correctamente supuso que una vez que una causa apropiada ha sido martilleada en la conciencia pública, no sería difícil inducir a sus "inocentes" — a los que Lenin motejó con anterioridad, y mayor crudeza, de "tontos útiles" - a contribuir con sus nombres, prestigio y fondos a "clubes de inocentes" bien organizados, manipulados por activistas situados en posiciones estratégicas — de preferencia no afiliados al Partido Comunista - y obtener así los resultados deseados. Quienes fueron invitados a incorporarse a estas organizaciones y, al parecer, a encabezarlas, eran invariablemente personajes bien intencionados y socialmente respetables, deseosos de cumplir un papel constructivo en la lucha por la justicia social y, al mismo tiempo, satisfacer su necesidad de justificación moral personal, y "que no se daban cuenta de que sus conciencias estaban siendo manejadas por agentes del gobierno de Stalin”25.

Aunque a los comunistas de la vieja guardia les causaba escalofríos ver a miembros ajenos al partido en posiciones políticas señeras, este enfoque resultó ser muy provechoso cuando se trataba de recaudar fondos y organizar el apoyo internacional para la República española. La maquinaria propagandística de Münzenberg presentaba la guerra como un enfrentamiento maniqueo entre las fuerzas del bien y del mal; entre el terror fascista y oscurantista de Franco, respaldado por mercenarios y reclutas bereberes, alemanes e italianos, por un lado, y una ilustrada, virtuosa y democrática república defendida por jóvenes héroes idealistas provenientes de todos los rincones del planeta. Logró convencer al resto del mundo que la República española era un paraíso socialdemócrata donde la tortura, las detenciones arbitrarias y las ejecuciones habían sido proscritas para siempre, y que ahora luchaba en defensa de la libertad, la democracia, la decencia elemental y la justicia para el pueblo español.

La campaña internacional logró su objetivo — pese a las suspicacias de Stalin - principalmente porque fue llevada adelante por un ingente número de “compañeros de ruta” y personajes influyentes en la opinión pública no afiliados a partido alguno, como periodistas, artistas, comentaristas, sacerdotes, ministros, académicos y actores, felices todos de ser invitados a manifestar su público apoyo al bando de la República española.

Un examen retrospectivo nos permite apreciar ahora que la facilidad con que Alec Digges, un veterano y disciplinado miembro del Partido Co-

${ }^{25}$ Stephen Koch, "Lying for the Truth...”, 2 de noviembre de 1993; también Koch, Double Lives..., 1944, pp. 19-30. 
munista, decidió en 1954 discutir con sus colaboradores la posible creación de Amnistía Internacional, significaba que la idea era de su autoría, o que bien que estaba añadiendo "prisioneros de conciencia” al repertorio de causas meritorias de Münzenberg. ¿Se reunieron alguna vez Alec y Willi? Hasta donde sabemos, Münzenberg no fue a España durante la guerra civil. No hice preguntas sobre el particular, porque sólo me enteré hace poco de la existencia de Münzenberg, dos décadas después del fallecimiento de Alec. No se puede descartar la posibilidad de que hayan sostenido un encuentro en 1938, cuando Alec viajaba a España por intermedio de la oficina de reclutamiento de la Brigada en París, pero es muy poco probable que Münzenberg haya tratado esos asuntos de políticas con el joven voluntario.

Si la idea fue de Alec, y él no la había discutido a fondo con sus colegas de partido, sería razonable suponer que tanto el Pacto entre España y Estados Unidos como la muerte de Stalin estuvieron presentes en su génesis. Antes de marzo de 1953, la lealtad y la obediencia del Partido al Kremlin habrían impedido cualquier jugarreta no autorizada, destinada a extender internacionalmente la labor de la Brigada. Incluso en 1954, sin quererlo, Alec se había adelantado a su época al formular esa imaginativa propuesta, destinada a explotar las reservas de decoro humanitario de los países de la alianza estadounidense y socavar así su autoridad moral. Sin embargo, su idea estaba acorde con los cambios que sobrevinieron a raíz del “discurso secreto” pronunciado por Jruschov con ocasión del Vigésimo Congreso del Partido Comunista, celebrado en 1956, en especial con la resurrección durante la Guerra Fría del espíritu de los fenecidos Comintern y Cominform, aunque esta vez encumbrado en las alas de una retórica que ignoraba la revolución mundial, pero exhortaba a los fieles a "encabezar la resistencia a los planes de expansión y agresión imperialista estadounidense en todas las esferas" ${ }^{26}$.

También cabe la posibilidad de que al asumir esta tarea, más antinorteamericana que revolucionaria, sin advertirlo Alec mantuvo vivo el espíritu original del Cominform y le proporcionó un objetivo práctico a una de las iniciativas de Münzenberg. Como en el gato de Cheshire, en Alicia el País de las Maravillas, el Cominform se había desvanecido, pero la mueca antinorteamericana no ha desaparecido. No resulta imposible sospechar que una consecuencia distante de la iniciativa de Münzenberg haya sido alentar a los entusiastas del post-Cominform a reactivar su anti-norteamericanismo ampliando el repertorio de "virtudes morales", incluyendo campañas a favor de la paz, la libertad, los árboles, los osos polares, la democracia, la capa de

${ }^{26}$ Alan Bullock, Hitler and Stalin, 1992, p. 924. 
ozono y el trato compasivo a los inmigrantes, y contra los cigarrillos, la discriminación racial, la obesidad, la globalización, la pena de muerte, el trabajo forzoso y la tortura. La experiencia de la Guerra Fría también habría confirmado la convicción de Münzenberg en cuanto a que, emprendidas urbi et orbi, esas campañas serían ignoradas dentro del mundo comunista, que se encontraba a salvo de una prensa y una opinión pública libres, pero socavarían la estatura moral de las políticas promovidas por los Estados Unidos y sus aliados.

Aun cuando Alec podía ser tan tenaz como persuasivo, la extraordinariamente franca discusión se prolongó hasta altas horas de la noche de esa jornada de noviembre de 1954, y surgieron varias objeciones prácticas que le llevaron a vacilar y aparentemente a reconsiderar su iniciativa. Era difícil, por ejemplo, pasar por alto la circunstancia de que ésta distraería los escasos recursos humanos y financieros disponibles para representar a los prisioneros en España, y además arriesgaba disipar el prestigio internacional acumulado durante la guerra civil y después de ella. Tampoco podía ignorarse un hecho que movía a reflexión: a pesar de que la Brigada se había esforzado al máximo, no se habían conseguido grandes logros, incluso para objetivos menos ambiciosos. En consecuencia, parecía poco realista, por no decir quijotesco, embarcarse en aquellos días en una campaña internacional tan exigente. Otro suceso que revistió al menos similar importancia fue nuestro inolvidable encuentro con Barbara Castle y Sidney Silverman, que obligó a descartar toda posibilidad de que Alec, o cualquiera de sus colegas del Partido Comunista, llegara a encabezar la nueva organización, si ésta pretendía conseguir la influencia y el respaldo público no partidista y moralmente intachable indispensables para prosperar.

Pensando en voz alta sobre este asunto, y haciéndonos presente las dificultades para conseguir alguien dispuesto a dirigir la nueva organización, Alec sugirió que Peter Benenson era la persona más capacitada para llevar las riendas de la nueva entidad y reclutar un comité ejecutivo compuesto por prestigiosos abogados e intelectuales británicos y extranjeros que simpatizaran con la causa. Visiblemente molesto, Peter preguntó si estaba siendo evaluado como candidato a tonto útil, y poniéndose de pie hizo ademán de retirarse, señalando que esa sugerencia era injusta, no le hacía gracia y no estaba dispuesto a dejarse utilizar de esa manera. A lo cual Alec replicó diciendo que sólo estaba bromeando, y que en todo caso Peter se equivocaba al pensar siquiera en la posibilidad de ser tratado de esa forma, 
pues él siempre sabía muy bien lo que estaba haciendo, a diferencia de los tontos útiles, quienes, por definición, nunca lo saben. Peter Benenson era un hombre inteligente, cultivado y altruista, cuya imagen ciertamente no daba la impresión de corresponder a la de los inocentes de Münzenberg, o a la de los tontos útiles de Lenin.

Restablecida la armonía, se sugirió que el capitán Hewitson se sentiría más que complacido de ocupar la presidencia, siempre que Alec hiciera el trabajo, pero con esto los temas se trivializaron y la discusión se hizo cada vez más anodina. Fue así como la velada culminó con la nueva iniciativa internacional de Alec sepultada bajo una andanada de chistes irlandeses, españoles y chilenos, y él acabó aceptando con desgano que lo más sensato era abstenerse de actuar, al menos por el momento.

En cuanto a mí, me reuní con Alec días más tarde y aproveché de recordarle que mi activa colaboración se debía enteramente al contacto que había establecido en mi niñez con refugiados republicanos que trabajaban conduciendo y reparando los camiones pesados de mi padre. Si bien tenía la mejor disposición a seguir cooperando con la campaña original de la Brigada a favor de los prisioneros, no estaba de acuerdo con que ésta se ampliara para ayudar a derrocar al gobierno español, objetivo que me parecía poco práctico y no necesariamente apropiado. Durante esos años me reuní en numerosas oportunidades con sobrevivientes de la guerra civil, y logré comprender en cierta medida la complejidad del trágico conflicto, que difería definitivamente de la descripción propagandística de Münzenberg como una simple pugna entre el bien y el mal. La lógica elemental parecía muy distante de Cataluña cuando un ex soldado comunista aventuró una hipótesis contraria a lo factual, y se preguntó qué curso habría seguido la guerra después de 1939, cuando Hitler y Stalin se abrazaban fraternalmente, si un régimen comunista hubiese triunfado en España. Menudo rompecabezas.

Lo que me quedó muy claro fue que las atrocidades cometidas por ambos bandos habían dejado tras de sí un legado de odio que hasta hoy no se ha desvanecido. En la década de 1950 resultaba por lo menos debatible la idea de que la restauración de la monarquía podría llevar a una reconciliación y reunificación de la sociedad española. Es más, también tuve que explicarle a mi buen amigo Alec que no compartía ni su sentimiento antinorteamericano post-Cominform de nuevo cuño, ni su lealtad de guerrero frío, y le pedí que no solicitara mi respaldo para su nueva iniciativa, si alguna vez ésta fructificaba. Él tomó todo esto con ecuanimidad. Ambos aceptamos nuestras diferencias de opinión y acordamos seguir trabajando juntos tal como habíamos hecho en el pasado. 
Entre 1954 y 1956 regresé un par de veces a España, pero en dos ocasiones no me fue posible viajar, y dada la urgencia del momento no me quedó más remedio que reclutar a mi hermana Carmen, en esa época alumna de la Central School of Speech and Drama de Londres, para que me reemplazara. Ella desempeñó su cometido con la buena voluntad, el encanto y la eficiencia que la caracterizaban, oficiando de intérprete para Peter Benenson, y encargándose de las discretas misiones locales que era preciso cumplir en Barcelona y Madrid. Mi inasistencia en dos oportunidades no tuvo nada que ver con mi amable desacuerdo con Alec. En marzo de 1954, meses antes de la reunión en Parton Street, fui a parar al hospital Middlesex tras haber levantado un baúl repleto de libros al mudarme a una vivienda en Nassau Street; la segunda vez, en agosto de 1955, me encontraba en los Estados Unidos.

En 1956 regresé a Chile y por algunos años perdí contacto con Alec, pero mi labor en la Universidad de Chile me permitió trabar relaciones con ex refugiados del Winnipeg que se habían quedado en el país y me aportaron nuevos puntos de vista sobre las complejidades de la Guerra Civil española. Es preciso citar nombres y comenzaré por Mauricio Amster, un artista, erudito y artesano comunista polaco, quien luchó en el Batallón Dombrowsky en la II Brigada, quedó inválido, sobrevivió a la guerra y llegó a Chile, donde no tardó en adquirir un sólido prestigio como brillante diseñador de libros. Tuve la fortuna de que diseñara mi primer libro para la Editorial Universitaria. Nos hicimos amigos, y me enteré de su desencanto con el marxismo y el historial criminal de los comunistas, en particular durante los "Días de Mayo” de Barcelona, cuando varios cientos de anarquistas y otros miembros de la izquierda no comunista fueron sistemáticamente asesina$\operatorname{dos}^{27}$.

Pero él no fue el único. El historiador Leopoldo Castedo recorrió un camino similar, desde enarbolar la bandera roja del comunismo español hasta la aflicción de ver traicionado su idealismo juvenil cuando los tanques rusos convencieron a los húngaros que debían comportarse, para transformarse finalmente en un reflexivo e ilustrado crítico de la alternativa soviética en la Guerra Fría. Lo mismo puede decirse del dramaturgo José Ricardo Morales, quien a última hora se abstuvo de seguir la senda roja hacia el futuro, tras haber presenciado el sanguinario comportamiento de los comu-

${ }^{27}$ Pese a sus reservas, Amster realizó una impecable traducción del Manifiesto y también diseñó su edición para la Editorial Universitaria (Marx y Engels, Manifiesto Comunista, traducido por Mauricio Amster, 1970); sobre los "Días de Mayo", véase Raymond Carr, Spain, 1808-1939, 1966, pp. 663-670; Hugh Thomas, The Spanish Civil War, 1977, pp. 651-653; Helen Graham, “Against the State: A Genealogy of the Barcelona May Days (1937)”, 1999, pp. 485-542. 
nistas cuando ocuparon, de hecho, cargos de poder. Sin duda alguna, sus agudas reflexiones y la amistad que me brindaron contribuyeron a distanciarme aún más de la versión de Münzenberg sobre el funesto conflicto.

A principios de la década de 1960 regresé a Londres y, varios meses después, hablé con Alec sobre el mítico nacimiento, en 1961, de Amnistía, que pronto pasó a llamarse Amnistía Internacional. Entre una y otra etapa. Tito rehusó doblegarse, Francia libró una guerra en Argelia, Perón fue depuesto, el Cominform fue desmantelado, polacos y húngaros se precipitaron a las calles, China inició una trasnochada revolución cultural, Castro tomó las riendas en Cuba mientras al otro lado del mundo empieza a perfilarse la tragedia vietnamita. Atendidas todas estas y otras circunstancias, Peter Benenson reconsideró la lejana propuesta de Alec Digges y aceptó asumir el liderazgo de Amnistía Internacional sin la ayuda de aquellos míticos estudiantes portugueses.

\section{REFERENCIAS BIBLIOGRÁFICAS}

Bergin, Thomas Goddard y Max Harold Fisch: The New Science of Giambattista Vico. Cornell University Press, 1970.

Berlin, Isaiah: Vico and Herder: Two Studies in the History of Ideas. Viking Adult 1976.

Bullock, Alan: Hitler and Stalin. Alfred A. Knopf, 1992.

Campbell, Andrew: "Double Lives: Three Australia Fellow Travellers in the Cold War". En National Observer (Summer 2007), № 71.

Carr, Raymond: Spain, 1808-1939. Clarendon Press, 1966.

Ferrer Mir, Jaime: Los Españoles del Winnipeg: El Barco de la Esperanza. Ediciones Cal Sogas, 1989.

Graham, Helen: "Against the State: A Genealogy of the Barcelona May Days (1937)”. En European History Quarterly, Vol. 29, № 4, October 1999.

Koch, Stephen: Double Lives: Stalin, Willi Münzenberg and the Seduction of the Intellectuals. Enigma Books, 1994.

"Lying for the Truth: Münzenberg \& The Comintern". En New Criterion, November 1993.

Malley, Bernard. Carta de Bernard Malley a Lord Templeton, Madrid, 9 de mayo de 1954. MS Templewood XIII (26): 50-55, Departament of Manuscripts \& University Archives, University of Cambridge Library.

Montefiore, Simon Sebag: Stalin: The Court of the Red Czar. Knopf, 2003.

O’Shaughnessy, Hugh: The Independent, February 28, 2005.

Power, Jonathan: “In the Face of Repression”. En The Guardian, May 12, 2001.

Rabben, Linda: “Amnesty's Roots”, extracto en internet de su libro Fierce Legion of Friends: A History of Human Rights Campaigners, 2002.

Royal Commission on Espionage, Parliamentary Debates (Hansard): 3 Eliz II, House of Representatives, October 28, 1954.

The Economist: Obituary, May 3, 2005. 
The National Archives (UK): "Communists, suspected communists and communist organizations", "The International Brigade Association”. United Kingdom: The National Archives KV 5/46-58.

Thomas, Hugh: The Spanish Civil War. Harper and Raw, $3^{\text {ra }}$ edición, 1977.

“The Spanish Civil War. Spain, 1936-1939”. En A. J. P. Taylor y J. M. Roberts (eds.), History of the Twentieth Century. Purnell Reference Books, 1979. 